\title{
INSKRIPSI HURUF ARAB DAN RAGAM HIAS PADA MASJID TUA AL-MUJAHIDIN KABUPATEN BONE SULAWESI SELATAN Suatu Tinjauan Arkeologis Deskriptif
}

\section{Inscriptions and Decorative of Arabic Letter to The Old Mosque Al-Mujahidin in Bone Regency, South Sulawesi an Archaeological Descriptive Overview}

\author{
Oleh: Muslihin Sultan* \\ *Dosen STAIN Watampone \\ Kantor: Jl. HOS. Cokroaminato Watampone Kab. Bone \\ Email: $\underline{\text { survamuslih(a),vahoo.com }}$
}

\begin{abstract}
Archaeology is history; archaeological research cannot be separatedfrom the history, because history reveals the story of material culture. The Old Mosque is part of a cultural thing that will describe the history of the Islamic society and the reconstruction of the mosque building in accordance with local cultural character of local genius in its time. The Old Mosque of al-Mujahidin Watampone is the oldest and the first mosque of the royal heritage of Bone in Islam development era. The mosque has specific stylistic and architecture that describes how the Islamic symbols interacted with local culture and art. The strong influence of Islamic teachings was implicitly reflected in a wide variety of the mosque ornaments. This research aims to reveal the decoration and Arabic inscriptions located in the Old Mosque, to promote the history and archaeological traces of the Islamic kingdom of Bone, and to recommend to the local government of Bone to make Qadi's cemetery as part of archeological history of the kingdom Bone that deserve to be considered by the community and the Government of Bone as a cultural heritage of the archipelago to be protected as Objects of Cultural guaranteed by Indonesian Law Number 5 of 1992 about Objects of Cultural Property. The research methodology was a field research with a survey which is descriptive, archaeological, historical, and explanative on the Old Mosque al-Mujahidin, Watampone, Bone regency, South Sulawesi. The techniques of collecting data in this study were: literature data, field data (archaeological assessment, observation, and interviews), documentation and recording, surface surveys, and the withdrawal of sampling. This study also used the architectural analysis on the mosque, i.e. morphological, technological, stylistic, and contextual analysis.
\end{abstract}

Keywords: Arabic Inscriptions and Ornamental Modes

\section{PENDAHULUAN}

$\mathrm{A}$ rkeologi, apapun padanan kata untuknya adalah disiplin yang mempelajari budaya dari masa lampau. Pertumbuhannya di Indonesia sejak awal sampai kini dipengaruhi oleh berbagai centris, baik yang datang dari Eropa Kontinental maupun Anglo-Saxon. Dewasa ini terdapat kecenderungan kuat untuk menyematkan arkeologi dalam antropologi, khususnyaAntropologi Budaya.

Obyek kajian arkeologi adalah seluruh peninggalan material dari masa lampau. Tinggalan tersebut sudah bisu, sehingga tidak dapat dijadikan responden untuk diwawancarai. Untuk itu arkeologi kemudian mengembangkan prosedur, tata dan metode kerja untuk dapat memanggungkan kembali peninggalan-peninggalan yang dijadikan sampel penelitian agar bisa ditentukan arti, kedudukan, fungsi dan pengoperasiannya. Keseluruhan ini memerlukan konseptualisasi bahasannya dan harus dapat dijadikan parameter bagi arkeologi itu sendiri. Dalam kaitan dengan ini, Binford menyatakan bahwa arkeologi merupakan pemasok data bagi rekonstruksi sejarah kebudayaan.

Tinjauan arkeologi merupakan ilmu yang mempelajari manusia dan masyarakat masa lalu melalui tinggalan budaya materi (material culture) seperti

Mujib.2009. Kaligrafi Arab di Indonesia (sejarah perkembangan dan penelitiannya, makalah. Ibid. 
bangunan-bangunan, alat-alat dan artefak lainnya. Colin Renfrew dan Paul Bahn menyebutkan bahwa arkeologi sebagai bentuk past-tense dari antropologi budaya yang juga mempelajari masyarakat dan kebudayaan manusia. Karena mempelajari masa lalu, maka arkeologi juga merupakan bagian dari sejarah, yaitu sejarah manusia secara luas yang dimulai sejak tiga juta tahun yang lalu.

Sejarah masyarakat Bone merupakan bagian dari sejarah Sulawesi Selatan yang harus mendapat perhatian untuk dikaji dan dikembangkan dalam berbagai perspektif, termasuk perspektif arkeologis historis, karena Bone adalah sebuah kerajaan besar dan popular di nusantara terutama pada abad ke-17 M, Raja Bone ke-15 Arung Palakka tampil sebagai penguasa Raja-raja di Sulawesi Selatan.

Tinggalan-tinggalan kerajaan Bone sebagai bagian dari sejarah bangsa, dapat dijadikan obyek penelitian arkeologis di antaranya: Istana, benda-pusaka, rumah adat, beberapa kompleks besar Makam Sultan/RajaRaja Bone yaitu di komplek Makam kalokko'e Bukaka, Makam Naga Uleng Cenrana dan Makam Laleng Bata Lamuru, serta satu komplek makam-makam Qadhi kerajaan Bone dan Masjid Laungnge atau Masjid Tua al-Mujahidin Kabupaten Bone.

Masjid Laungnge merupakan sebutan akrab bagi masyarakat Bone atau istilah bahasa Bugis dari masjid Tua al-Mujahidin. Masjid ini merupakan masjid pertama dalam sejarah kerajaan Bone yang dibangun pada masa Raja Bone ke-13 La Maddaremmeng sebagaimana ditulis oleh Asnawi Sulaeman. Masjid ini memiliki ciri dan ragam hias arsitektur bangunan yang identik dengan masjid-masjid tua (kuno) di pulau Sulawesi, Jawa dan Sumatera. Di antara ciri masjid Tua al-Mujahidin sebagai masjid kuno adalah beratap tumpang dan memiliki balubu yang terbuat dari keramik cina (konon kabarnya keramik berasal dari masa dinasti Ming) dan memiliki inskripsi berhuruf Arab pada hiasan masjid dan mimbar. Hal tersebut bermakna bahwa ragam hias arsitektur masjid tua di Bone memiliki kesinambungan budaya (countinus-change) di tengah pergulatan dan persebaran Islam di masyarakat Nusantara.

Sebenarnya peran dan fungsi masjid pada masa awal Islamisasi Indonesia tidak terlepas dari proses masuknya Islam di Indonesia. Sebagaimana kita ketahui, ada beragam proses Islamisasi di Indonesia. Menurut Uka Tjandrasasmita dalam bukunya Dedi Supriyadi bahwa kedatangan Islam dan penyebarannya di kepulauan Indonesia adalah dengan cara damai di antaranya melalui saluran perdagangan, perkawinan, ajaran tasawuf, pendidikan, kesenian, dan politik.

Dari berbagai cara penyebaran Islam itulah, menurut Ahmad Mansur Suryanegara pada akhirnya mengerucut pada pembangunan Masjid sebagai pusat atau lembaga pendidikan pada masa awal Islamisasi Indonesia untuk mendidik dan membina generasi muda yang pada perkembangan selanjutnya di Indonesia dikenal dengan istilah pesantren.

Demikian pula pendirian Masjid-Masjid pada masa awal Islamisasi di Indonesia, seperti Masjid Demak, Masjid Sang Cipta Rasa Cirebon, Masjid Al Aqsha Kudus (Masjid Menara Kudus) dan Masjid Agung Banten. Selain memainkan peran sebagai lembaga pendidikan Islam, juga merupakan legitimasi kekuasaan kesultanan Islam pada waktu itu.

Snouck Hurgronje pernah mengatakan sebagaimana dikutip oleh Pijper, bahwa masjid di Indonesia dibandingkan dengan masjid di Negara Islam lainnya merupakan pusat pengaruh agama Islam terhadap kehidupan penduduk secara keseluruhan, bahkan menurutnya orang yang ingin meneliti kehidupan keagamaan di salah satu pulau di Indonesia seperti Jawa, harus mulai dengan mempelajari masjid. Ernest Renan pernah berkata bahwa saya tidak pernah masuk ke sebuah masjid, tanpa menimbulkan emosi. ${ }^{5}$ Hal ini menunjukkan bahwa begitu penting pengaruh masjid bagi ummat Islam.

Oleh karena itu, eksplorasi dan penelitian arkeologis tentang masjid tua al-Mujahidin kabupaten Bone, menjadi penting untuk dilakukan karena di masjid inilah sejarah dakwah dan pendidikan Islam tumbuh dan berkembang pada masa awal Islam di Kerajaan Bone sampai sekarang, mengingatBoneduhulu adalah salah satu kerajaan besar di Sulawesi Selatan yang memiliki peran signifikan dalam catatan sejarah tersebarnya Islam di jazirah Sulawesi pada abad ke17 bersama dengan kerajaan-kerajaan Islam lainnya.

\footnotetext{
Irmawati Marwoto-johan. 2009. Peran Arkeologi dalam Kajian Islam Nusantara, (makalah disampaikan pada Diklat Arekeologi Keagamaan, Jakarta.

+ Sebagaimana misalnya masjid Sang Cipta Rasa Cirebon yang didirikan oleh Sunan Gunung Djati bersama Pangeran Tjakrabuana dengan bantuan dari para Wali Songo, menjadi simbol kekuasaan Keraton Cirebon. http://cerminseiarah.blogspot.com/2010/06/pendahuluan.html. Masjid dan Upacara Keagamaan Islam: Pengertian, Fungsi dan Aspek-aspek Historisnya, diakses pada tgl 24 juni 2010.
} 
Penelitian ini dimaksudkan untuk menggali nilai-nilai budaya historis Islam yang sangat berharga untuk dilestarikan.

\section{Tinjauan Pustaka}

Kajian tentang masjid kuno di Indonesia khususnya di Jawa mulai dilakukan pada tahun 1920, oleh N.J Krom yaitu tentang menara Kudus yang diperkirakan berasal dari abad ke $16 \mathrm{M}$ dan dianggap merupakan gaya bangunan peralihan dari gaya bangunan Majapahit yang mengingatkan pada bangunan candi. Kemudian dilanjutkan oleh J.E Jasper pada tahun 1922 yang mengkhususkan pada penelitian seni ukir dan seni bangunan. Hasil penelitiannya menunjukkan bahwa seni ukir dan seni bangunan di Kudus merupakan seni bangunan JawaHindu Majapahit. ${ }^{6}$ Steinmann pada tahun 1934 melakukan penelitian ornamen yang terdapat pada masjid Mantingan dan makam Ratu Kalinyamat. Menurut pendapatnya penelitian tentang jenis tanaman sangat penting untuk mengetahui keragaman tumbuhan yang ada pada masa itu. Selain itu ia melakukan penelitian pola-pola ornamennya dan dibandingkan dengan ornamen di candi-candi.?

Penelitian tentang menara dan masjid kuno di Indonesia dilakukan oleh Dr. GFPijper pada tahun 1947, Pijper menyampaikan bahwa masjid kuno di Indonesia pada umumnya memiliki menara. Menara di masjid Kudus asalnya bukan menara, melainkan bangunan dari zaman Hindu yang digunakan kembali sebagai tempat kulkul. Tentang bangunan masjid kuno ia menyampaikan bahwa bentuknya mengikuti bentuk arsitektur lokal dengan beberapa ciri seperti denah segi empat dan pejal, atapnya bertingkat-tingkat.

Lebih jauh Pijper membuat beberapa kategori ciriciri masjid Tua di Jawa yaitu; pertama, masjid itu mempunyai denah dasar persegi, kedua, tidak berdiri di atas tiang-tiang seperti langgar di Jawa, rumah tinggal di Indonesia yang kuno, tajug di daerah Sunda dan bale di Banten, tetapi berdiri di atas pondasi padat yang agak tinggi, ketiga, mempunyai atap meruncing yang terdiri dari 2 sampai 5 tingkat dan mengecil ke atas; keempat, di sisi barat atau sisi barat laut terdapat bangunan menonjol untuk mihrab; kelima, di bagian depan dan kadang-kadang kedua sisinya, ada serambi yang terbuka atau tertutup; keenam, halaman sekitar masjid dikelilingi oleh tembok dengan satu atau dua pintu gerbang, kemudian ditambahkan bahwa ciri khas masjid di Jawa adalah dibangun di sebelah barat alunalun (sebuah lapangan persegi yang ditanami rumput).

Tentang asal usul bangunan masjid kuno juga telah dibahas oleh beberapa ahli seperti H.J de Graaf yang mengatakan bahwa masjid kuno di Jawa mendapat pengaruh bentuk masjid dari Sumatera yaitu masjid Taluk di Sumatera Barat yang merupakan prototipe masjid Malabar. D.R. W.F Stutterheim mengajukan pendapatnya bahwa masjid kuno di Indonesia mendapat pengaruh dari bangunan tempat menyabung ayam di Bali. Pendapat Stutterheim disangkal oleh Prof Sutjipto Wiryosuparto, bentuk denah masjid Taluk adalah segi empat dan dikelilingi air, sedangkan masjid Malabar denahnya persegipanjang tidak dikelilingi air, jadi berbeda dan yang sama hanya pada bentuk atap. Selanjutnya jika bagunan tempat menyabung ayam sebagai bangunan yang semiprofan tidak mungkin dijadikan dasar pembuatan masjid. hal lain adalah tidak memiliki loteng. Sutjipto lalu mengajukan bangunan mandapa atau pendapa yang menjadi asal mula bentuk masjid kuno. ${ }^{10}$

Penelitian tentang tulisan Arab merupakan perkembangan lebih lanjut dari alphabet semiotik yang terdiri atas sebagian besar konsonan dan hanya tiga huruf saja yang merupakan huruf vokal bunyi panjang (long-vowel). Melalui Muhammad saw, huruf Arab yang kemudian menjadi bahasa resmi agama Islam yang selanjutnya menjadi bahasa universal. Sebelum tumbuhnya Islam, alphabet Arab memang telah berkembang mengarah kepada seni kaligrafi, misalnya dalam tradisi pra-Islam di Arab dalam perlombaan menyusun syair sebagaimana yang dikemukakan A. Schimel, Tetapi Nabi Muhammad yang "buta huruf (Ummiy) menyebarkan wahyu melalui Alquran menjadikan kaligrafi sebagai seni Islam yang berestetika tinggi yang Ilahiyyah."

${ }^{\text {s}}$ GF. Pijper. 1984. Studien Over De Geschiedenis Van De Islam in Indonesia 1900-1950, diterjemahkan oleh Prof. Dr. Tudjimah dan Dra Yessy Augusdin, dengan Judul, Beberapa Sludi Tentang Sejarah Islam di Indonesia 1900-1950, Jakarta, Ul-Press; h. 14-15

'Irmawati Marwoto-Johan, Op.Cit., h. 3

'Ibid.

"Ibid.

'G.F. Pijper. Op.cit., h. 15

10 Irmawati Marwoto-Johan, Op.cit

"Hasan Muarif Ambary. 2001. Menemukan Peradaban, Jejak Arkeologis dan Historis Islam Indonesia. Jakarta, PT. Logos Wacana Ilmu: h. 171 
Menurut Ambary, sejak awal tepatnya ketika kertas belum ditemukan dan pohon papyrus merupakan bahan media penulisan- kertas ditemukan pada $750 \mathrm{M}$ - telah terdapat dua tipe tulisan yang menjadi cikal bakal perkembangan seni kaligrafi. Dua tipe tulisan tersebut adalah tipe gaya naskh yang berbentuk miring (cursive) dengan bundaran-bundaran yang dituliskan dengan tipe kufi. Tipe yang terakhir ini sangat popular. Ia dipakai secara luas oleh masyarakat Mekkah, Madinah dan Kufah sehingga kemudian dijadikan huruf resmi untuk menuliskan Alquran. ${ }^{12}$

Gaya kufi secara umum bersudut (angular) sering pula ditemukan berupa ukiran atau pahatan pada makam, prasasti dan mata uang, lebih sebagai bahan epigrafi dari masa sebelum berlangsungnya kekuasaan Dinasti Umayyah (66-750). Pada abad ke 11 M, di Iran muncul jenis huruf kufi yang telah mengalami perkembangan segi artistiknya, menjadi lebih panjang dan ramping, yang kemudian dikenal dengan gaya qarmthian kufque dan dianggap sebagai bentuk terbaik dari contoh tulisan khat Arab. Sementara gaya naskh yang berkembang hingga sekarang-ternyata lebih popular dan menjadi semakin umum dipakai dunia Islam. ${ }^{13}$

Seorang peneliti kaligrafi, Ibnu Nadim, menyatakan bahwa paling tidak terdapat dua belas gaya tulisan pokok dengan dua belas variasi dalam kaligrafi Islam. Namun sangat sukar untuk mencari bukti tipologi yang banyak itujika hanya mengamati buktibukti dari Alquran, baik yang tertulis di atas papyrus ataupun kertas. Ibnu Nadim dalam hal ini menyebut sebuah gaya di luar kufi dan naskh, yang disebutnya sebagai tulisan "setengah" (nishf) yakni yang disebut gaya thuluthain (dua pertiga) atau "sepertiga" (thuluth). Ibnu Muqla mengklasifikasikan enamjenis tulisan kaligrafis yang berkembang di dunia Islam yakni: Sulus, naskh, rihan, muhaqqaq, tauqi, riqa. Karena itu, para ahli kaligrafi kemudian berpendapat bahwa "ibu" dari kaligrafi Arab adalah sulus dan dan kemudian naskh. Sementara orang Persia, terutama kalangan seniman, mengembangkan sebuah gaya lain, yang disebut ta 'liq (menggantung) yang sebenarnya merupakan pengembangan lebih lanjut dari riqa dan tauqi yang dikerjakan secara teliti dan sungguh-sungguh. Inilah yang kemudian berkembang menjadi tulisan yang lazim dipakai di dunia Islam sekarang ini. ${ }^{14}$

Penelitian masjid kuno juga pernah dilakukan oleh Syafwandi yang meneliti tentang Menara Masjid Kudus dalam Tinjauan Sejarah dan Arsitektur, beliau berpendapat bahwa menara masjid Kudus merupakan bangunan kuno hasil dari akulturasi antara kebudayaan Hindu-Jawa dengan Islam. Bahkan sangat mungkin terdapat pula unsur kebudayaan Indonesia asli ditilik dari ornamennya. ${ }^{15}$ Pada penelitian tersebut terdapat perdebatan beberapa arkeolog tentang bentuk manara masjid kudus.

Di antara hasil seni bangunan Islam yang sangat menonjol menurut Uka Tjandrasasmita yaitu masjidmasjid kuno di Indonesia kekhasan corak atau bentuk bila dibandingkan dengan corak masjid-masjid di negeri lain. Kekhasan corak seni bangunan masjid itu mungkin disebabkan faktor universalitas yang terkandung dalam pengertian masjid menurut hadis dan tidak adanya aturan yang dicantumkan dalam ayat-ayat Alquran tentang bagaimana seharusnya membuat bangunan masjid, kecuali arahnya yang disebut kiblat. Dengan demikian dalam dunia Islam kalangan arsitek dan masyarakat muslim mempunyai kebebasan untuk berkreasi membuat bangunan masjid. ${ }^{16}$

Sedangkan penelitian tentang kerajaan Bone telah banyak dilakukan khususnya pada kajian sejarah politiknya yang tersebar di berbagai media dan jurnal ilmiah, Hamdan Juhannis menulis bahwa mungkin tidak ada yang sangsi akan kebesaran Kerajaan Bone bila membaca literatur sejarah tentang daerah ini. Sebut misalnya buku The Heritage of Arung Palakka, karya monumental Leonard Y. Andaya, dikemukakan bahwa kebesaran Bone bisa ditelusuri dari sejarah pengaruh politiknya yang pernah menyeberang sampai ke Kerajaan Siam. Peran Bone dalam sejarah juga terlihat pada literatur Islamisasi di pulau Sulawesi, kerajaan Bone menjadi salah satu pelaku pentingterhadap proses Islamisasi itu, misalnya dengan hadirnya Lontara Latoa yang menjadi rujukan terpenting terhadap jejak sejarah implementasi syariat Islam di Sulawesi Selatan. Dalam sejarah Islamisasi, dikenal istilah musu selleng karena penolakan Bone

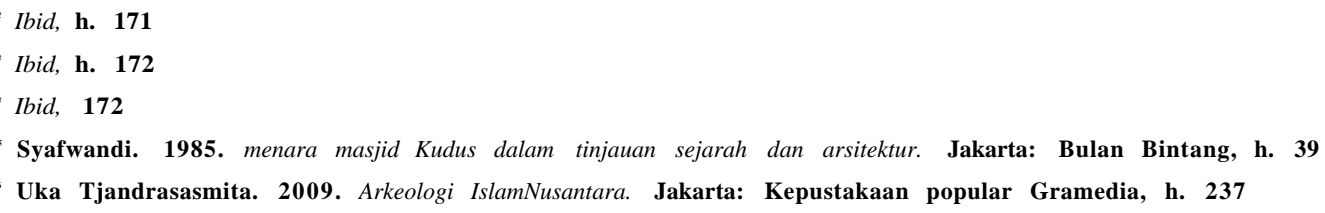


terhadap politik Islamisasi yang dilancarkan Kerajaan Gowa. Selanjutnya Bone kemudian menjadi penganut kerajaan Islam yang taat. Kebesaran Bone, juga bisa terlihat dari diskursus Rumpana Bone (Bobolnya Bone) yang menandai penguasaan total atas pemerintah Belanda terhadap kerajaan-kerajaan yang ada di Sulawesi Selatan saat itu. ${ }^{17}$

Sejarah masuknya Islam juga dapat dijumpai referensi penting di antaranya yang ditulis oleh Andi Muhammad Ali dengan judul Selayang Pandang Sejarah Bone, dalam buku tersebut digambarkan secara singkat perjalanan kerajaan Bone dari awal terbentuknya, masuknya Islam, terjadinya perang antara Kerajaan Bone dan Kerajaan Gowa pada masa Arung Palakka, terjadinya kontak antara kerajaan Bone dengan Belanda dengan niat awal sebagai "teman" untuk membantu Kerajaan Bone dan kerajaan-kerajaan Bugis lainnya untuk lepas dari penjajahan Kerajaan Gowa. Kelebihan dari buku A. Muhammad Ali ini dibandingkan dengan buku sejarah yang lain adalah memaparkan sejarah Kerajaan Bone dengan paparan singkat tanpa menghilangkan makna substansi dari sejarah peristiwa dan tokoh raja Bone itu sendiri. Selain dari buku A. Muh. Ali terdapat juga buku lain yang menulis tentang kerajaan Bone di antaranya Andi Palloge Petta Nabba, Sejarah Kerajaan Tanah Bone. Buku terakhir ini lebih tajam membahas tentang sejarah politik dan sosial kerajaan Bone. ${ }^{18}$

Satu referensi yang turut memberi gambaran sejarah budaya kabupaten Bone adalah tulisan Mattulada dkk, dengan judul Agama dan Perubahan Sosial, mengupas tentang sejarah masuknya Islam, pendidikan Islam, membahas tentang peran parewa sara atau begelar Petta Kali 'e atau Qadhi, sebagai pemuka agama dalam acara-acara Islam di Kerajaan Bone. ${ }^{19}$ Penelitian lain yang juga memberi informasi tentang sejarah masjid Tua al-Mujahidin Watampone yaitu tulisan Asnawi Sulaeman yang berjudul Sejarah Singkat Keqadhian (Qadhi) Kerajaan Bone Tahun 1629-1951 M. dalam buku tersebut diuraikan secara sederhana tentang perjalanan Qadhi dan perannya di tengah masyarakat Islam serta sejarah berdirinya masjid Tua al-Mujahidin. ${ }^{20}$ Penelitian lain yang berkaitan dengan masjid Tua al-Mujahidin yaitu hasil penelitian Saudil Arabiyyah yaitu Makna dan Fungsi Mustaka Masjid Tua al-Mujahidin." $\quad$ Saudil lebih banyak meneliti tentang balubu masjid Tua, menurut Tawalinuddin antara mustaka dan balubu sangat berbeda makna filosofisnya, sehingga beliau lebih setuju menyebutnya balubu dari pada istilah mustaka.

Dengan demikian, tentunya penelitian ini sangat berhubungan dengan penelitian yang lalu, berkaitan dengan penelitian masjid kuno di Indonesia, hal tersebut telah dilakukan oleh para arkeolog pada masjid-masjid kuna di Jawa dan Sumatra, akan tetapi penelitian tentang masjid Tua Bone belum ditemukan khususnya meneliti tentang ragam hias dan inskripsi Arab yang ada, oleh karena itu semua referensi di atas memberi gambaran tentang penelitian masjid dan sejarah politik dan budaya Kerajaan Bone, sedang kajian ini adalah penelitian arkeologi historis pada Masjid Tua alMujahidin dengan pengkajian ragam hias model dan bentuk tulisan Arab, sehingga disinilah letak perbedaannya dengan penelitian terdahulu.

\section{PEMBAHASAN}

\section{Sejarah Masjid Tua al-Mujahidin Watampone}

Alamat lengkap lokasi penelitian ini yaitu di lingkungan Laleng Bata Desa/Kelurahan Bukaka, Kecamatan Tanete Riattang, Kabupaten Bone Provinsi Sulawesi Selatan, dan masjid ini terletak di jalan Sungai Citarum kota Watampone.

Masjid Laungnge merupakan sebutanyang akrab bagi masyarakat Bone dalam bahasa Bugis, kemudian diberi nama masjid Tua al-Mujahidin, ini merupakan masjid pertama dalam sejarah Kerajaan Bone yang dibangun pada masa Raja Bone ke-13 La Maddaremmeng sebagaimana ditulis oleh Asnawi Sulaeman, terdapat juga pendapat yang lain yang mengatakan bahwa masjid Tua dibangun pada masa Raja Bone ke-22 (1749-1775) yang bergelar Sultan Abd. RazakJalaluddin yaitu pada tanggal 15 September 1752. ${ }^{22}$ Kedua pendapat ini tampak bertentangan tetapi

\footnotetext{
17 Hamdan Juhannis, 2007. Bone dan Tantangan Kebesarannya (Catatan Menyambut Hari Jadi Ke-677 Kabupaten Bone) diterbitkan di Harian Tribun Timur.

is Andi Palloge. 1990. Sejarah Kerajaan Tanah Bone.

19 Mattulada, dkk. 1984. Agama dan Perubahan Sosial. Rajawali Press, Jakarta.

20 Asnawi Sulaiman. 2004. Sejarah Singkat Keqadhian (Qadhi) Kerajaan Bone Tahun 1629-1951 M,

${ }^{21}$ Saudil Arabiyah. 1993. Makna dan Fungsi Mustaka Masjid Tua al-Mujahidin (Skripsi fakultas Adab; IAIN Alauddin)

22 Saudil Arabiyah. Ibid, h. 25.
} 
dapat dikompromikan secara logika sederhana bahwa Masjid ini pada awalnya dibangun pada masa pemerintahan Lamaddaremmeng, kemudian baru disempurnakan pada masa raja La Temmasonge.

Hingga sekarang ini, Masjid Tua al-Mujahidin berdiri dengan megahnya di bagian utara kota Bone, merupakan bangunan bergaya atau berarsitektur zaman madya Indonesia, di zaman itu budaya Islam sangat tampak mendominasi corak khusus seni budaya Indonesia, maka Islam sangat besar pengaruhnya.

Pada umumnya corak masjid kuno di Indonesia yang menjadi perhatian khusus yaitu: (a) atapnya melingkupi ruang bujur sangkar, kubah, atap masjid inilah yang dominan menjadi ciri dari seni Islam, (b) ada tidaknya menara sebagai tempat muazzin menyerukan azannya pada tiap kali tiba waktu shalat, (c) letak masjid selalu didirikan sedekat mungkin dengan istana, di ibukota kerajaan atau tempat kedudukan seorang adipati. ${ }^{23}$

Masjid Tua al-Mujahidin tergolong masjid istana, karena di sebelah selatan istana terdapat alun-alun sementara masjid Tua al-Mujahidin terletak sebelah barat alun-alun, sebagaimana diketahui bahwa alunalun merupakan sarana penting suatu kerajaan sebagai arena latihan prajurit dan sekaligus tempat pertemuan raja dan rakyatnya.

Masjid ini terletak di desa Bukaka kelurahan Laleng Bata kecamatan Tanete Riattang Kabupaten Bone, letaknya $173 \mathrm{~km}$ dari kota Makassar, letaknya sebelah utara kota Watampone, sebelah timur sekretariat PC. IPNU Bone, sebelah selatan terdapat makam Qadhi Bone dan sebelah barat terdapat makam para Raja-Raja Bone dan keluarganya serta terdapat pula lembaga-lembaga pendidikan Islam (Raudhatul Athfal dan Madarasah Ibtidaiyah), sebelah utara jalan Sungai Cenrana.

Berdasarkan data yang ditemukan oleh Saudil Arabiyah, Masjid Tua al-Mujahidin telah dilakukan empat kali pemugaran bentuk: Pertama, pada tahun 1775 oleh Raja Bone ke-24 Toappatunru Matinroe ri Laleng Bata bergelar Sultan Ismail Muhtajuddin. Penampilan sesudah perombakan masih memakai atap tradisional yang bersusun tiga dengan corak yang lebih runcing dan curam, dengan atap-atap tambahan yang serupa tapi dalam ukuran yang lebih kecil untuk mengatapi bangunan-bangunan tambahan. Atap dari bangunan tambahan tersebut bentuknya sama dengan atap bangunan induk dan berjumlah dua buah, sehingga perubahan masjid itu tidak kehilangan simetri dari bangunan masjid sebelumnya.

Kedua, pemugaran dan perbaikan masjid dilakukan pada tahun 1890 oleh Raja Bone ke-31 La Pawawoi Karaeng Sigeri Matinroe ri Bandung (18951905) pada masa penjajahan Belanda, perombakan bangunan masjid dengan mengganti material bangunan yang sudah lapuk dan rapuh, dari segi bentuk bangunan masih dipertahankan seperti semula.

Ketiga, pemugaran masjid Tua dilakukan pada tahun 1922 oleh Qadhi Bone KH. Abd. Hamid, yakni pada masa kedudukan Belanda dalam pusat pemerintahan Afdeling Bone dan Onder Afdeling Bone, perubahan yang paling tampak adalah pada bentuk atapnya, merupakan usaha untuk merubah bentuk corak susunan atap tradisional sebelumnya, untuk diganti dengan atap kubah.

Keempat, bantuan dari Gubernur Sulawesi Selatan H. Andi Oddang, didirikan menara yang berdiri terpisah dari masjid (bagian belakang sebelah timur), menempati posisi sebelah kanan masjid yang khas sebagai hasil karya arsitektur dengan struktur beton yang menonjol dan dominan. ${ }^{24}$

\section{Analisis Arsitektur Bangunan Masjid Tua Watampone}

Bentuk denah Masjid Tua al-Mujahidin adalah bujur sangkar, Kaki bangunan ditinggikan, dinding berhias kaligrafi Arab, pintu berdaun ganda, bentuk pintu persegi panjang, daun pintu persegi panjang, memiliki Jendela berdaun ganda 2 buah, berdaun tunggal 4 buah, bentuk jendela persegi panjang 6 buah, daun jendela persegi panjang 6 buah, ventilasi membulat pada bagian atas pintu, pembagian ruangan yaitu bangunan utama, serambi depan dan serambi samping kanan dan kiri, serta terdapat pula tempat shalat khusus perempuan (pewesteran [jw]) pada serambi sebelah kanan, terdapat pula menara masjid, halaman masjid, tempat berwudhu laki-laki dan perempuan.

Pada bagian atap terdapat kubah kecil di bagian atas, berbentuk tumpang, tiang berbentuk segi empat, di atas kubah terdapat kemuncak berupa keramik yang dalam istilah bugis Bone disebut balubu, terdapat pula mihrab berbentuk lengkung sebagai salah satu ciri masjid Tua/Kuno di Indonesia. $\begin{array}{lll}{ }^{23} & \text { Ibid, } & \mathbf{3 2} \\ & \text { Ibid, } & \mathbf{3 8 - 3 9}\end{array}$ 
Pembagian halaman yaitu 1 halaman depan dan 1 halaman samping, pada bagian bahan kaki terbuat dari bata, semen, pasir dibalut dengan tegel keramik (hasil pemugaran), bahan dinding terbuat dari bata, semen, pasir dibalut dengan tegel keramik (hasil pemugaran)..$^{25}$

Bahan pada bingkai pintu terbuat dari kayu, bahan daun pintu terbuat dari kayu, bahan bingkai jendela terbuat dari kayu, bahan daun jendela terbuat dari kayu, bahan atap terbuat dari seng, bahan kemuncak keramik (balubu dalam bahasa Bugis, konon kabarnya dari Cina), bahan tiang terbuat dari bata, semen, pasir, tegel, konstruksi bata dengan pengait, konstruksi dinding yaitu bata dengan pengait, konstruksi rangka atap yaitu kayu dengan pasak, hiasan kaki yaitu berbentuk punden berundak hiasan pada keramik,

Hiasan dinding yaitu kaligrafi Arab, hiasan pintu yaitu polos hiasan tiang tidak ada, hiasan atap yaitu kubah dengan kemuncak balubu, Gaya arsitektur: Bugis, Cina dan Jawa, panjang halaman: 37,55 m, lebar halaman: $26,25 \mathrm{~m}$, panjang denah: $20 \mathrm{~m}$, lebar denah: 24,85 m, Jumlah Umpak: 2 buah (ditambah'l kubah dan 1 keramik balubu), tebal dinding: $35 \mathrm{~cm}$, tinggi dinding: $4,43 \mathrm{~cm}$.

Untuk ukuran Tinggi pintu: Pintu utama sebanyak 3 buah panjang 2,10 m, dan pintu kecil (6 buah) panjang $2,30 \mathrm{~m}$, serta pintu imam (lbuah), pintu khusus perempuan (1 buah), adapun ukuran lebar pintu yaitu: untuk Pintu Utama (3 buah) memiliki lebar 1,27 m, sedangkan untuk pintu kecil (sebanyak 6 buah) memiliki lebar $1,10 \mathrm{~m}$.

Ukuran tinggi jendela: $1,74 \mathrm{~m}$, dengan lebar jendela: $1,03 \mathrm{~m}$, tinggi tiang: 4,08 m, tebal tiang: $1,3 \mathrm{~m}$, adapun jumlah tiang dalam ruang utama masjid sebanyak: 4 buah, sedangkan jumlah tiang pada serambi masjid sebanyak 18 buah.

Jumlah jendela 9 buah terdiri atas 2 buah jendela di dalam ruang utama masjid dan 6 buah di ruang shalat untuk perempuan letaknya di serambi kanan masjid, adapun jumlah ventilasi: 27 buah (11 buah dalam raung utama masjid, 16 buah di bawah kubah bagian atas).

Dilihat dari segi arsitektur masjid, dapat dikatakan bahwa ciri masjid kuno masih dipertahankan misalnya jumlah pintu besar sebanyak sembilan buah pintu. ${ }^{26}$
Mihrab masjid dengan model lengkungan, tempat shalat bagi perempuan, dan mimbar masjid juga masih terjaga bentuk aslinya.

\section{Inskripsi Arab dan Ragam Hias Masjid}

Sejumlah masjid yang memperlihatkan kekhasan arsitektur masjid-masjid kuno adalah masjid agung Demak, Masjid Agung Banten, Masjid Agung Kesepuhan Cirebon, Masjid Agung Yogyakarta, Masjid Agung Surakarta, Masjid Agung Palembang, Masjid Raya Ternate, Masjid Raya Baiturahman-dulu Banda Aceh, Masjid Indra Puri Aceh, Masjid Agung Sumenep, Masjid Angke Jakarta dan masih banyak lagi. ${ }^{27}$ Demikian pula halnya Masjid Tua al-Mujahidin yang ada di Watampone memiliki kesamaan ciri-ciri dengan masjid-masjid yang disebutkan oleh Uka Tjandrasasmita.

Peneliti menemukan beberapa inskripsi Arab dan ragam hias masjid Tua al-Mujahidin yang dapat dijelaskan sebagai berikut; Ayat-ayat yang tertulis di masjid bagian depan kanan adalahQS. al-Baqarah: 144:

Ayat-ayat yang tertulis di masjid bagian kiri adalah QS. al-Baqarah ayat 10-11:

$$
\operatorname{so~} \mathbf{J}^{\wedge} \mathbf{v} \wedge_{->r^{\wedge}} \quad \mathrm{J} ? \operatorname{cf} \mathbf{r}^{\wedge} \wedge \mathbf{j} \mathbf{j}{ }^{\text {" }} \text { of } \mathrm{WP}^{\prime} \mathrm{J}
$$

Ayat-ayat yang tertulis di masjid bagian dinding sebelah kiri adalah QS. al-nur ayat 36-37:

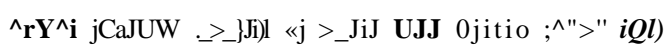

Ayat-ayat yang tertulis di masjid bagian dinding belakang ruang utama adalah QS. Ali Imran ayat 193-194:

13 'jiite $£^{\prime} j$ itlli LSvJ> I u ) f $\quad<£ ? £ \quad 12<*="$ ^।

\footnotetext{
${ }^{25}$ Mahyuddin, Wawancara, di Watampone pada tanggal 25 Juli 2010

${ }^{26}$ Sembilan pintu masjid bermakna empat sahabat besar (Abu bakar, Umar Usman dan Ali), empat malaikat utama (Jibril, Mikail, Israfil, Israil) dan Nabi Muhammad Saw. semuanya berjumlah Sembilan orang, pendapat yang lain adalah makna pintu Sembilan adalah Sembilan Wali (Wali Songo) bagi orang Jawa.
} 
Ayat-ayat yang tertulis di masjid bagian serambi depan adalah QS. al-Zariyat ayat 55-56:

dan dalam QS. Ali Imran ayat 133:

Ayat-ayat yang tertulis di masjid bagian serambi samping kiri adalah QS. al-Taubah ayat 128:

$$
\text { p-£^ip } \quad j>-f^{\wedge} S^{*} \quad \text { jJ } \quad \text { J } \quad \wedge £ t X>r \quad \boldsymbol{J L} J
$$

dan dalam QS. Al-Araf ayat 204:

Ayat-ayat yang tertulis di masjid bagian serambi samping kanan posisi depan adalah QS. al-Nahl ayat 98:

dan dalam QS. al-Baqarah ayat 45-46:

dan dalam QS. al-Isra' ayat 111:

Jill $\wedge$ jj ij $\wedge$

Pada bagian tempat shalat untuk perempuan terdapat tulisan asmaul husna' yang jumlahnya 101 nama, bukan 99 nama, hal ini disebabkan karena kata

$\left.j^{*}\right)$ dimasukkan dan kata (fi/Y $\mathbf{j} \mathbf{J}^{\wedge} \mathbf{j}-\mathbf{O}$ dipisahkan dalam bentuk tulisan yang berdiri sendiri (J"*iriji) dan (fijOfj)- Inskripsi pada hiasan masjid yang terletak pada bagian sisi kiri diatas jendela posisi depan, samping mihrab yaitu hadis Nabi Saw:

$$
l^{\wedge} \mathrm{f} \wedge^{\wedge} \wedge j^{\wedge} j J S^{\prime} j l^{\wedge}-t \quad j y l ! i U i
$$

Artinya:

Muhammad saw bersabda: Barangsiapa yang bershalawat kepadaku 100 kali pada hari jumat, maka dia akan dibangkitkan pada hari qiamat dengan disertai cahaya, seandainya cahaya itu mau dibagikan di antara seluruh makhluk, maka cahaya itu masih jauh lebih luas. ${ }^{2 *}$

Inskripsi pada hiasan masjid yang terletak pada bagian sisi kanan di atas jendela besar posisi depan samping mihrab yaitu hadis Nabi Saw:

$\left.\langle\mathrm{U} \gg \wedge j) \lambda J i 4 i J a^{\wedge} 4\right]$ Oyip $0 y$ ijt* $4 \ll-\gg \mathrm{Jl}$

Artinya:

Diriwayatkan dari nabi saw sesunggauhnya beliau bersabda: barangsiapa yang bershalawat kepadaku pada hari Jum 'at sebanyak seratus kali, maka Allah akan mengampuni dosanya selama 80 tahun.

Inskripsi pada mimbar masjid yaitu ada dua hal yaitu satu hadis Nabi saw dan satu ayat al-Quran, teks hadis berikut ini:

dan Teks ayat yaitu:

Tulisan Arab atau teks hadis juga masih ditemukan pada bagian mihrab masjid yaitu:

Tulisan Basmalah pada bagian depan di atas lengkungan mihrab dengan model kaligrafi kufi. Teksnya sebagai berikut:

(ill J j J U > ) illjj $4 \mathrm{iU} \ll l y \wedge{ }^{\wedge} \wedge \mathrm{J} j \mathrm{ji} 0 \mathrm{~L} »$

Terdapat dua buah balubu pada kemuncak atap masjid dan balubu pada kemuncak mimbar. Terdapat ragam hias pada tiang mimbar berupa sulur-sulur daun dan lantai keramik pada mimbar. Demikian deskripsi tentang ragam hias dan inskripsi Arab pada masjid Tua al-Mujahidin Watampone.

\section{PENUTUP}

\section{Kesimpulan}

Masj id Laungnge merupakan sebutan yang akrab bagi masyarakat Bone dalam bahasa Bugis, kemudian diberi nama masjid Tua al-Mujahidin, ini merupakan masjid pertama dalam sejarah kerajaan Bone yang dibangun pada masa Raja Bone ke-13 La Maddaremmeng

${ }^{27}$ Ibid. h. 239

${ }^{28}$ Hadis ini ditemukan dalam maktabah syamilah bahwa hadis ini diriwayatkan oleh abu nuaim da;lam kitab al-hilyah dari Ali bin alhusin bin Ali dari baDaknva dari neneknva.

(tV/A) $\sim 4 j J-\backslash J \sim M i$

$\left(\mathbf{O}^{\wedge} \mathbf{r} j * * J J S . J s-J>O \mathbf{O j}-\mathbf{J}-\mathbf{I}<J i\right.$

$\sim 4 J-\backslash \mathbf{J}$ (8) 
sebagaimana ditulis olehAsnawi Sulaeman, terdapat juga pendapat yang lain yang mengatakan bahwa masjid Tua dibangun pada masa Raja Bone ke-22 (17491775) yang bergelar Sultan Abd. Razak Jalaluddin yaitu pada tanggal 15 September 1752. Kedua pendapat ini tampak bertentangan tetapi dapat dikompromikan secara logika sederhana bahwa Masjid ini pada awalnya dibangun pada masa pemerintahan Lamaddaremmeng kemudian baru disempurnakan pada masa raja La Temmasonge.

Dilihat dari segi arsitektur masjid Tua, maka dapat dikatakan bahwa ciri masjid kuno masih dipertahankan, misalnyajumlah pintu besar sebanyak sembilan buah pintu, mihrab masjid dengan model lengkungan, tempat shalat bagi perempuan, dan mimbar masjid juga masih terjaga bentuk aslinya. Ragam hias masjid Tua alMujahidin adalah Tulisan khat tsulus pada diding masjid ruang utama bagian dalam dan luar, isnkripsi khat Arab tsulus hadis Nabi pada hiasan dinding masjid, dan inskripsi Arab pada mimbar masjid serta ragam hias sulur-sulur daun pada mimbar masjid.

\section{Ucapan Terima Kasih}

\section{DAFTAR PUSTAKA}

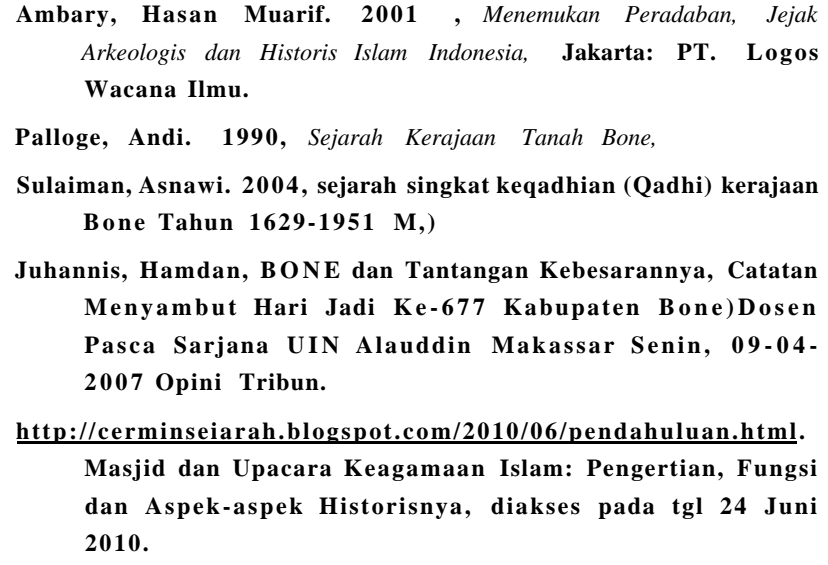

http://cerminseiarah.blogspot.com/2010/06/pendahuluan.html. Masjid dan Upacara Keagamaan Islam: Pengertian, Fungsi dan Aspek-aspek Historisnya, diakses pada tgl 24 Juni 2010 .

http://www. bone, go. id/geografi.php. diakses pd tgl 12 Nov. 2009
Johan, Irmawati Marwoto, Jakarta. 2009. Peran Arkeologi dalam Kajian Islam Nusantara, makalah disampaikan pada Diklat Arekeologi Keagamaan.

Mahyuddin, Wawancara, di Watampone pada tanggal 25 Juli 2010

Margono S. $\mathbf{2 0 0 4}$ Metodologi Penelitian Pendidikan, Jakarta: Rineka Cipta.

Mattulada, dkk. 1984. Agama dan Perubahan Sosial, Jakarta: Rajawali Press

Mattulada. tth. Islamisasi di Sulawesi Selatan. Makalah.

Mujib. 2009. Kaligrafi Arab di Indonesia, Sejarah Perkembangan dan Penelitiannya, makalah.

Pijper, GF. 1984. Studien Over De Geschiedenis Van De Islam in Indonesia 1900-1950, diterjemahkan oleh Prof. Dr. Tudjimah dan Dra Yessy Augusdin, dengan Judul, Beberapa Studi Tentang Sekarah islam di Indonesia 1900-1950, Jakarta; Ul-Press. 